\title{
Hemiarthroplasty for proximal humerus fractures
}

\author{
Lauchlan Chambers • Joshua S. Dines • Dean G. Lorich • \\ David M. Dines
}

Published online: 25 January 2013

(C) Springer Science+Business Media New York 2013

\begin{abstract}
Proximal humerus fractures are common injuries that are increasing in incidence with the aging of the population. While nonoperative treatment of some fracture patterns results in clinical success, other, more displaced and comminuted fractures may require surgery to ensure a successful outcome. It is important to evaluate both patient and fracture characteristics in deciding upon the appropriate type of treatment. Every effort should be made to perform a humeral sparing procedure in younger patients. In the elderly, especially with more complex four-part fractures and fracture dislocations, hemiarthroplasty and reverse total shoulder arthroplasty are indicated to decrease complication rates and improve functional outcomes. In hemiarthroplasties, it is critical to achieve proper implant height and positioning of the tuberosities. For those patients or fractures in which the tuberosities are unlikely to heal or cannot be adequately reconstructed, reverse total shoulder arthroplasty should be considered.
\end{abstract}

Keywords Hemiarthroplasty · Fracture · Proximal humerus · Reverse total shoulder replacement

\section{Introduction}

Proximal humerus fractures account for $4 \%-5 \%$ of all fractures and typically occur in a bimodal distribution in older women as a result of low-energy falls or in younger

J. S. Dines · D. G. Lorich • D. M. Dines

Hospital for Special Surgery, 535 East 70th Street,

New York, NY 10021, USA

L. Chambers $(\bowtie)$

Sports Medicine and Shoulder Surgery,

Hospital for Special Surgery, 535 East 70th Street,

New York, NY 10021, USA

e-mail: chambersk@hss.edu men as a result of high-energy trauma [1,2]. With continued advancement of techniques and implants such as locking plates, surgical fixation of proximal humerus fractures has been increasing in popularity. However, the reported complication rates in humeral head preserving procedures continue to be high. In particular, the rate of osteonecrosis remains unchanged even with the most modern of techniques. It is clear that the prevalence of osteonecrosis after proximal humerus fractures increases over time. In one group treated with percutaneous fixation, $26 \%$ of patients went on to develop osteonecrosis at an intermediate followup of 50 months; in patients with four-part fractures, that percentage increased to an alarmingly high rate of $50 \%$ [3].

In a recent series of 294 proximal humerus fractures treated with ORIF, a total of $28.2 \%$ of patients had complications, most commonly screw cutout, requiring $24.5 \%$ of patients to undergo revision surgery [4]. The most important factors leading to a negative outcome were smoking and fracture type; either a fracture dislocation or a nonimpacted metaphyseal surgical neck fracture (AO type 11-A3) was significantly associated with secondary screw cutout and osteonecrosis [4]. Fractures with a humeral head split and complex three- and four-part fractures are also at risk for the development of malunion and osteonecrosis after internal fixation $[5,6]$. Both shoulder hemiarthroplasty and, more recently, reverse total shoulder arthroplasty (RTSA) are indicated for these more complex fractures with high complication rates with humeral head preserving procedures.

\section{Clinical evaluation}

Most patients with displaced proximal humerus fractures will present to an acute care facility with pain, loss of function, and swelling of the involved upper extremity. It is critical to obtain a detailed history not only of the trauma and the mechanism of injury, but also of any medical 
comorbidities, especially in the elderly. It is important to assess for endocrine, cardiac, and neurologic risk factors that may have contributed to a syncopal event. As with other orthopedic injuries, the patient's functional baseline, hand dominance, walking ability, and a history of fracture or osteoporosis should be documented.

On physical examination, significant swelling of the shoulder and upper arm is usually visible, with extensive ecchymoses becoming visible approximately 24-48 hours after the trauma. The shoulder may be gently manipulated to assess for unified motion or the presence of crepitus. A full secondary survey may be performed to rule out concomitant injuries such as head trauma in the elderly after a fall. Assessment of lateral shoulder sensation and isometric deltoid motor function may be performed to rule out an axillary nerve injury. Distal neurologic testing may also be carried out to rule out a brachial plexus injury.

\section{Imaging}

Initially, standard shoulder radiographic views should be completed, consisting of a true AP, a transscapular $\mathrm{Y}$, and an axillary. If there is difficulty in obtaining the axillary view due to a patient's pain or apprehension, a modified axillary view such as a Velpeau view can be obtained, allowing the patient to remain comfortable in a sling. It is our practice to routinely order CT scans with 3-D reconstruction views in all cases in which we are considering operative intervention. These studies provide important information regarding bone quality, fracture displacement, or the presence of an articular or head-splitting component. For preoperative planning of arthroplasty, an AP view of the contralateral humerus is used to template the planned length and height of the implant (Fig. 1).

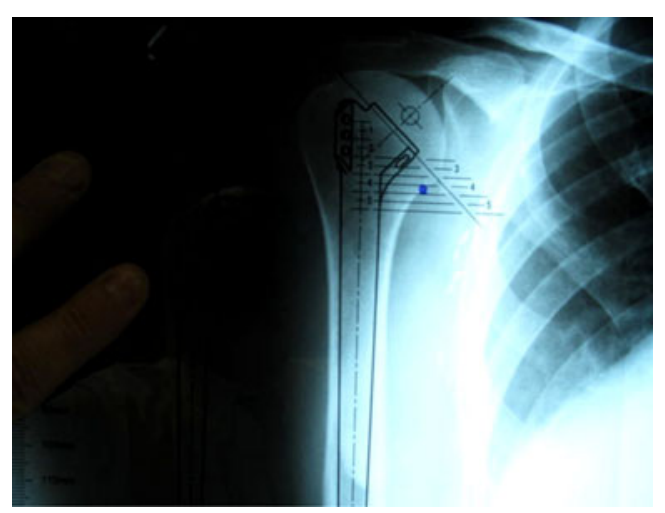

Fig. 1 An AP view of the contralateral humerus should be used to template the planned length and height of the implant for complete preoperative planning

\section{Fracture classification}

The Neer classification system is based on the anatomic relationship of four segments: the humeral shaft, greater tuberosity, lesser tuberosity, and articular surface; each segment is considered a separate part in the fracture if there is more than $1 \mathrm{~cm}$ of displacement or $45^{\circ}$ of angulation [7]. Although the Neer classification has demonstrated poor inter- and intraobserver reliability, it is still commonly used, due to its simplicity [8]. A recent study found a significantly higher agreement on treatment recommendations than on fracture classification, suggesting that the low interobserver reliability of the Neer classification may have less clinical importance [9].

The AO/ASIF and a binary system described by Hertel et al. are two classification systems that attempt to predict the potential for humeral head ischemia and, ultimately, osteonecrosis $[10,11]$. The AO/ASIF groups fractures into three main groups and additional subgroups based on fracture location, status of the surgical neck, and the presence of a dislocation. Hertel et al. demonstrated that the basic fracture type as classified by their system, the integrity of the medial hinge, and the length of the dorsomedial metaphyseal extension were the strongest predictors of ischemia [11]. Interestingly, the presence of osteonecrosis does not universally lead to a poor outcome. In patients undergoing nonlocking fixation of complex proximal humerus fractures, Wijgman et al. reported that $77 \%$ of patients who developed osteonecrosis had a good or excellent result [12].

\section{Natural history/Nonoperative treatment}

It is important first to understand the natural history of nonoperative management of a condition in order to appreciate the added benefit of surgical intervention, arthroplasty or otherwise. It is clear, especially in proximal humerus fractures, that the individual characteristics of both the fracture and patient ultimately dictate the final outcome of nonoperative treatment. Court-Brown et al. provided compelling evidence that impacted valgus proximal humerus fractures do not need to be fixed surgically, demonstrating a good or excellent result in over $80 \%$ of patients treated nonoperatively [13].

However, the preferred treatment becomes less clear in more displaced fractures, especially in the elderly. Edelson et al. studied the natural nonoperative history of more complex fractures that are usually treated surgically [14]. They utilized a 3-D classification system and found that more extensive and comminuted fractures did marginally poorer with regard to motion, as compared with three-part injuries. Although malunion was universal, most of the patients eventually became pain free, with sufficient motion and strength to perform basic activities of daily living. They 
describe that even in the most severe proximal humerus fracture, the clinical result is similar to that achieved with a successful shoulder fusion. These results are similar to those of other natural history studies showing improved results with less displacement and comminution and lower functional scoring and motion in three- and four-part fractures, but with reasonable patient satisfaction $[15,16]$. However, these studies are primarily retrospective and are limited to lower levels of evidence.

\section{Indications for arthroplasty}

The indications for arthroplasty fall into two categories: patient characteristics and fracture characteristics. Patients are required to be medically stable in order to tolerate extensive surgery and be able to actively participate in rehabilitation after surgery. Fracture characteristics include head-splitting patterns, fracture dislocations, and displaced three- and four-part fractures not amenable to surgical fixation (Fig. 2) [17]. Krishnan et al. found that age is the most important consideration in the surgical management of proximal humerus fractures. Patients greater than 70 years of age should undergo arthroplasty over osteosynthesis because of poor neuromuscular control and osteoporotic bone leading to poor fixation [18]. They also outlined three other factors to guide treatment: bone quality, fracture pattern, and the timing of surgery-acute ( $<4$ weeks) or chronic ( $>4$ weeks) [18]. However, several studies by Lorich et al. have demonstrated excellent outcomes with surgical fixation using a medial endosteal implant in poorer quality bone with comminution, emphasizing the importance of medial column support [19•, 20,21]. In a group of 27 patients who were either older than 70 years or had sustained a fracture with medial comminution, using this technique, $96 \%$ of patients maintained their original reduction, and there were no cases of screw perforations or evidence of osteonecrosis [19•].

Hemiarthroplasty is the most common choice for arthroplasty, but RTSA is increasing in popularity. Tuberosity healing is critical for a successful outcome after hemiarthroplasty; the presence of any factors that make this difficult may indicate the need for RTSA. In the presence of severe tuberosity or metaphyseal comminution, comorbidities that would decrease tuberosity healing, cuff tear arthropathy, or a failed hemiarthroplasty, RTSA is preferred over hemiarthroplasty $[17,22]$.

\section{Operative treatment}

Kontakis et al. performed a systematic review and analyzed 810 hemiarthroplasties in 16 studies with a mean follow-up

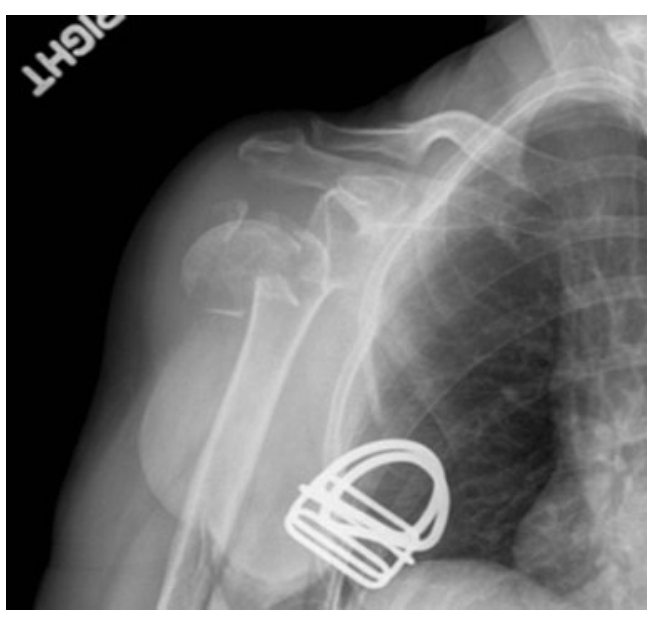

Fig. 2 More complex fractures, like this four-part fracture dislocation, are usually not amenable to surgical fixation

of 3.7 years [23]. They found complications related to fixation and healing of the tuberosities in $11.15 \%$ of patients. While most patients had minimal pain, the mean forward elevation was $105.7^{\circ}$, mean abduction was $92.4^{\circ}$, and most had persistent and significant limitations of function at final follow-up [23].

There are some level I data consisting of randomized controlled trials (RCTs) comparing nonoperative treatment and hemiarthroplasty for four-part fractures. Boons et al. recently completed an RCT looking at 50 patients 65 years and older randomized to either hemiarthroplasty or nonoperative treatment [24]. They found the nonoperative group had more pain at 3 months, but the same by 12 months; otherwise, they observed no true advantages in treatment with hemiarthroplasty in terms of quality of life and function [24]. However, an RCT out of Sweden comparing hemiarthroplasty with nonoperative treatment yielded conflicting results. In 55 patients with a mean age of 77, a significant improvement in quality of life and reduction in pain was demonstrated in the hemiarthroplasty group at 2-year follow-up [25••].

A more recent RCT conducted in Norway demonstrated no difference in functional outcome at 1-year follow-up for displaced three- or four-part fractures treated with either an angular stable plate or nonoperatively [26••]. This suggests that arthroplasty may be superior to surgical fixation of displaced proximal humerus fractures in the elderly. In contrast, for younger patients, every attempt should be made at surgical fixation to avoid the potential complications of prosthetic replacement $[27,28]$. The determination of who is elderly should focus less on chronologic age and more on physiologic age, activity level, and the presence of osteoporosis.

It has been clearly shown that the outcomes of hemiarthroplasty depend on the original underlying diagnosis. Most recently, Gadea et al. concluded that the best survival 
rates occur in the setting of rheumatoid arthritis and osteonecrosis, while the worst occur with the primary diagnosis of rotator cuff arthropathy and fracture, with 10-year prosthesis survival of $81.5 \%$ and $76.8 \%$, respectively [29]. However, in terms of function, the mean Constant-Murley score after 8 years was higher in patients with fracture than in those with rheumatoid arthritis or cuff tear arthropathy [29].

The outcomes for hemiarthroplasty are usually excellent if the tuberosities heal and poor if the greater tuberosity does not heal. Liu et al. looked at 33 patients undergoing hemiarthroplasty for fracture and found that healing of the tuberosities was poor in 18 patients; those patients with abnormal tuberosity healing had significantly higher pain scores and lower functional outcomes [30]. In contrast, the outcomes of RTSA for proximal humerus fractures are generally more consistent. In 43 patients undergoing RTSA for three- and four-part fractures, Bufquin et al. showed that although there was displacement of the tuberosities in $53 \%$ of patients, the clinical outcome was satisfactory, with mean forward elevation of $97^{\circ}$ and mean modified Constant score of $66 \%$ [31]. Although the outcomes of RTSA for fracture are comparable to those of hemiarthroplasty, they are indeed less influenced by tuberosity healing. Boyle et al. compared functional outcomes between RTSA and hemiarthroplasty for acute proximal humerus fractures in 368 patients [32]. Although the RTSA patients were older (79.6 vs. 71.9 years), they had a significantly better 5-year Oxford Shoulder Score than the hemiarthroplasty group, with no differences in revision rates or mortality.

\section{Authors' preferred technique}

In patients with fracture types that meet the previously described indications, arthroplasty is performed. The patient is placed in the beach chair position with the head of the bed

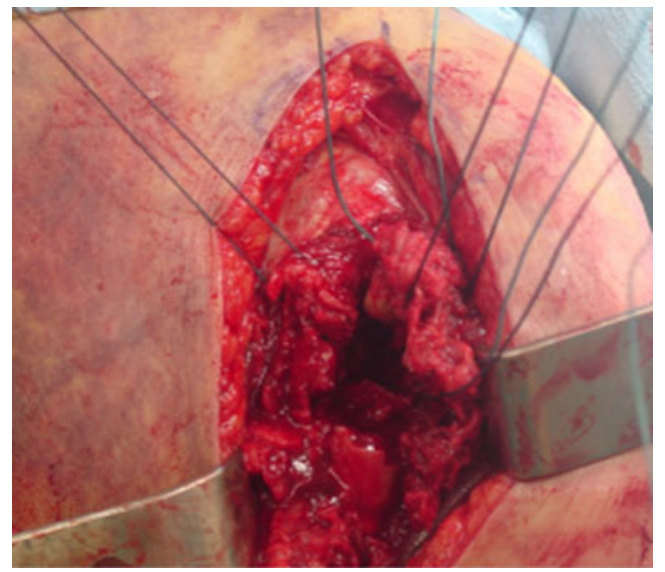

Fig. 3 One or two sutures are placed in the lesser tuberosity fragment, and three in the greater tuberosity

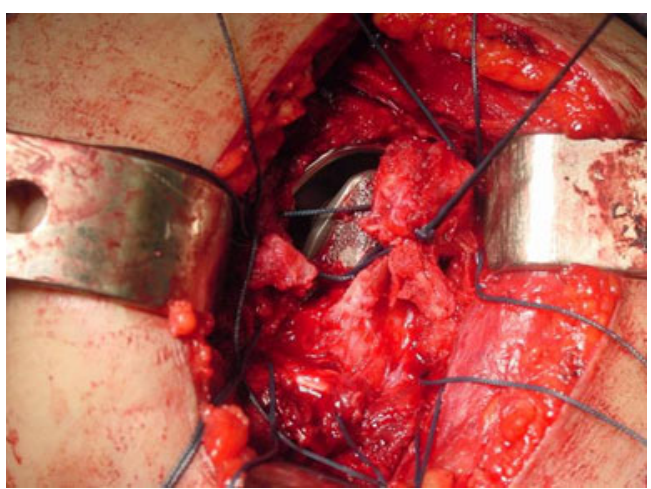

Fig. 4 The previously placed greater tuberosity sutures are brought inside-out through the lesser tuberosity; the greater tuberosity is then fixed $0.5 \mathrm{~cm}$ distal to the top of the humeral head

elevated approximately $45^{\circ}$. It is important that the freely draped arm can be extended while at the patient's side. A deltopectoral approach is used. Typically, significant adhesions and hematoma are encountered that need to be removed from the subdeltoid space. The bicipital groove is a critical landmark. The fracture line between the tuberosities is almost always located just posterior to the groove. The first part of the procedure involves getting control of the tuberosity fragments. In cases of arthroplasty for three-part fractures, one must osteotomize the lesser tuberosity from the humeral head, in essence creating a four-part fracture. The humeral head is removed, after which the tuberosities are tagged with heavy sutures. Three sutures are placed at the bone-tendon interface of the greater tuberosity, and one or two are placed in the lesser tuberosity fragment (Fig. 3). When possible, the use of different-colored sutures makes suture management easier later in the case.

Next, the humeral canal is exposed and prepared with sequential reaming. On the basis of physician preference, an intramedullary or an extramedullary positioning device may be used to ensure proper height. Preoperative films and implant measurements can also be used to assess component

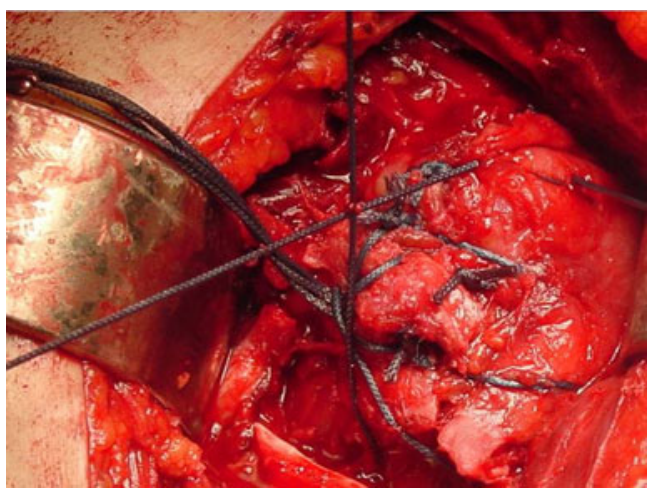

Fig. 5 The top and bottom sutures through the lesser tuberosity are tied, reducing the lesser to the greater tuberosity. Finally, the shaft suture is brought over top the tuberosities in figure-of-eight fashion 
position. Murachovsky et al. have demonstrated that the top of the pectoralis major tendon can also be used to assess height, since it is, on average, $5.6 \mathrm{~cm}$ below the top of the humeral head [33]. Measuring any large medial metaphyseal fragments will also help gauge the correct height.

Two drill holes are created $1.5 \mathrm{~cm}$ distal to the fracture site, and sutures are passed prior to cementing. One suture in placed longitudinally in the more posterior drill hole from outside-to-in, going from inferior to superior, which will be used to provisionally fix the greater tuberosity to the fracture stem. The second suture is placed transversely from anterior to posterior to be used as a figure-of-eight suture through both tuberosities at the end of the procedure, after they have been fixed to the stem and each other. A fracture-specific humeral component is cemented in place with approximately $20^{\circ-} 30^{\circ}$ of retroversion. Once the cement has hardened, closed reduction with a trial head is performed to assess the stability. We prefer $50 \%$ translation of the head on the glenoid in the anterior, posterior, and inferior directions. Once satisfied, the final humeral head component is placed.

A successful outcome in the setting of hemiarthroplasty ultimately relies on the tuberosities healing anatomically, and it is initially dependant on suture fixation. Systematic suture tying is critical, since many sutures are used, which can make management challenging. The middle sutures through the greater tuberosity are brought around the implant and through the implant fins. Next, the longitudinal suture placed through the drill hole in the humeral shaft is brought around the greater tuberosity. Next, the top and bottom sutures previously placed in the greater tuberosity are brought inside-out through the lesser tuberosity (Fig. 4). The greater tuberosity is then placed against the anterior fin of the implant and fixed $0.5 \mathrm{~cm}$ distal to the top of the humeral head. The middle sutures and the posterolateral shaft suture are securely tied. The top and bottom sutures through the lesser tuberosity are then tied to reduce the lesser to the greater tuberosity. The suture that was placed in the humeral shaft is finally used over the top of the tuberosities in a figure-of-eight fashion (Fig. 5).

A final closed reduction is performed to check the stability of the repair and range of motion. A minimum of $150^{\circ}$ of forward elevation and stable internal and external rotation should be achieved. A portable radiograph is obtained immediately postoperatively to assess the position of the implant and tuberosities. If an RTSA is instead indicated, the principles of implant height and fixation of tuberosities are similar. This is covered in much more detail in other articles.

\section{Conclusion}

Proximal humerus fractures are the most common fracture of the shoulder girdle and are a significant health-care burden, especially in the elderly population. It is crucial to perform a full clinical evaluation, including relevant imaging, in order to treat these injuries appropriately. Both patient factors and injury factors should be closely scrutinized in choosing the need for and the type of surgical intervention. Patient factors include age, quality of bone, and the presence of comorbidites, while injury factors include fracture pattern and timing of injury. In more complex and displaced fractures in osteoporotic bone, hemiarthroplasty is most commonly performed. To ensure clinical success in hemiarthroplasty, the tuberosities need to be reconstructible and possess the potential to heal. If not, an RTSA should be considered. The likelihood of a successful outcome can be viewed in descending order with a hemiarthroplasty, with reconstructible tuberosities being most likely, followed by an RTSA without reconstructible tuberosities and, finally, a hemiarthroplasty without reconstructible tuberosities [34].

Disclosure L. Chambers: none; J. S. Dines: consultant to BioMimetics, Conmed Linvatec, Tornier Sports Medicine; D. G. Lorich: none; D. M. Dines: Board Member and Treasurer, Journal of Shoulder and Elbow Surgery, consultant to Tornier, BioMimetics, receives royalties from Bimet.

\section{References}

Papers of particular interest, published recently, have been highlighted as:

- Of importance

•- Of major importance

1. Green A, Norris T. Proximal humerus fractures and fracture dislocations. In: Browner B, Jupiter J, Levine A, Trafton P, editors. Skeletal trauma: basic science, management and reconstruction. 3rd ed. Philadelphia: Saunders; 2003. p. 1532-624.

2. Court-Brown CM, Garg A, Mc-Queen MM. The epidemiology of proximal humeral fractures. Acta Orthop Scand. 2001;72(4):365-71.

3. Harrison AK, Gruson KI, Zmistowski B, et al. Intermediate outcomes following percutaneous fixation of proximal humeral fractures. J Bone Joint Surg Am. 2012;94(13):1223-8.

4. Spross C, Platz A, Rufibach K, et al. The PHILOS plate for proximal humeral fractures-risk factors for complications at one year. J Trauma Acute Care Surg. 2012;72(3):783-92.

5. Connor PM, Flatow EL. Complications of internal fixation of proximal humeral fractures. Instr Course Lect. 1997;46:25-37.

6. Gerber C, Werner CM, Vienne P. Internal fixation of complex fractures of the proximal humerus. J Bone Joint Surg Br. 2004;86 (6):848-55.

7. Neer II CS. Displaced proximal humeral fractures: I. Classification and evaluation. J Bone Joint Surg Am. 1970;52(6):1077-89.

8. Gumina S, Giannicola G, Albino P, et al. Comparison between two classifications of humeral head fractures: Neer and AO-ASIF. Acta Orthop Belg. 2011;77(6):751-7.

9. Brorson S, Olsen BS, Frich LH, et al. BMC Surgeons agree more on treatment recommendations than on classification of proximal 
humerus fractures. Musculoskelet Disord. 2012;13(1):114 [Epub ahead of print].

10. Müller ME. Appendix A: The comprehensive classification of fractures of long bones. In: Müller ME, Allgöwer M, Schneider $\mathrm{R}$, Willenegger $\mathrm{H}$, editors. Manual of Internal Fixation: Techniques Recommended by the AO-ASIF Group. 3rd ed. Berlin: Springer; 1991. p. 118-25.

11. Hertel R, Hempfing A, Stiehler M, Leunig M. Predictors of humeral head ischemia after intracapsular fracture of the proxi- mal humerus. J Shoulder Elbow Surg. 2004;13(4):427-33.

12. Wijgman AJ, Roolker W, Patt TW, Raaymakers EL, Marti RK. Open reduction and internal fixation of three and four-part fractures of the proximal part of the humerus. J Bone Joint Surg Am. 2002;84:1919-25.

13. Court-Brown CM, Cattermole H, McQueen MM. Impacted valgus fractures (B1.1) of the proximal humerus. The results of nonoperative treatment. J Bone Joint Surg Br. 2002;84(4):504-8.

14. Edelson G, Safuri H, Salami J, Vigder F, Militianu D. Natural history of complex fractures of the proximal humerus using a three- dimensional classification system. J Shoulder Elbow Surg. 2008;17(3):399-409.

15. Rasmussen S, Hvass I, Dalsgaard J, Christensen BS, Holstad E. Displaced proximal humeral fractures: results of conservative treatment. Injury. 1992;23(1):41-3.

16. Zyto K. Non-operative treatment of comminuted fractures of the proximal humerus in elderly patients. Injury. 1998;29(5):349-52.

17. Dines DM, Warren RF. Arthroplasty for proximal humerus fractures. In: Dines DM, Lorich DG, Helfet DL, editors. Solutions for complex upper extremity trauma. New York: NY, Thieme; 2008. p. 79-87.

18. Krishnan SG, Bennion PW, Reineck JR, Burkhead WZ. Hemiarthroplasty for proximal humeral fracture: restoration of the Gothic arch. Orthop Clin North Am. 2008;39(4):441-50. vi.

19. • Hettrich CM, Neviaser A, Beamer BS, Paul O, Helfet DL, Lorich DG. Locked plating of the proximal humerus using an endosteal implant. J Orthop Trauma. 2012;26(4):212-5. This study analyzed a group of 27 patients undergoing locked plating of the proximal humerus using a medial endosteal implant, most commonly fibular allograft. They found only one patient who underwent loss of fixation and no cases of AVN or implant failure.

20. Neviaser AS, Hettrich CM, Dines JS, Lorich DG. Rate of avascular necrosis following proximal humerus fractures treated with a lateral locking plate and endosteal implant. Arch Orthop Trauma Surg. 2011;131(12):1617-22. Epub 2011 Aug 4.

21. Neviaser AS, Hettrich CM, Beamer BS, Dines JS, Lorich DG. Endosteal strut augment reduces complications associated with proximal humeral locking plates. Clin Orthop Relat Res. 2011;469(12):3300-6.

22. Frankle MA, Chacon-Balados A, Cuff D. Reverse shoulder prosthesis for acute and chronic fractures. In: Dines DM, Laurencin CT, Williams GR, editors. Arthritis and Arthroplasty: The Shoulder. Philadelphia: PA, Saunders; 2009. p. 218-31.
23. Kontakis G, Koutras C, Tosounidis T, Giannoudis P. Early management of proximal humeral fractures with hemiarthroplasty: a systematic review. J Bone Joint Surg Br. 2008;90(11):1407-13.

24. Boons HW, Goosen JH, van Grinsven S, van Susante JL, van Loon CJ: Hemiarthroplasty for humeral four-part fractures for patients 65 years and older: a randomized controlled trial. Clin Orthop Relat Res 2012. [Epub ahead of print]

25. • Olerud P, Ahrengart L, Ponzer S, Saving J, Tidermark J. Hemiarthroplasty versus nonoperative treatment of displaced 4part proximal humeral fractures in elderly patients: a randomized controlled trial. J Shoulder Elbow Surg. 2011;20(7):1025-33. Epub $2011 \mathrm{Jul}$ 23. This randomized trial compared hemiarthroplasty versus conservative management for four-part humeral fractures in the elderly. They demonstrated less pain in the hemiarthroplasty group, accounting for a significant improvement in quality of life, without a difference in range of motion.

26. •- Fjalestad T, Hole MØ, Hovden IA, Blücher J, Strømsøe K. Surgical treatment with an angular stable plate for complex displaced proximal humeral fractures in elderly patients: a randomized controlled trial. J Orthop Trauma. 2012;26(2):98-106. This study is one of the few randomized controlled trials comparing surgical fixation with conservative management for displaced proximal humerus fractures in the elderly. They found evidence of improved radiographic outcomes in the surgically treated group, but not improved functional outcomes.

27. Sperling JW, Cuomo F, Hill JD, et al. The difficult proximal humerus fracture: tips and techniques to avoid complications and improve results. Instr Course Lect. 2007;56:45-57.

28. Thanasas C, Kontakis G, Angoules A, Limb D, Giannoudis P. Treatment of proximal humerus fractures with locking plates: a systematic review. J Shoulder Elbow Surg. 2009;18(6):837-44.

29. Gadea F, Alami G, Pape G, Boileau P, Favard L: Shoulder hemiarthroplasty: Outcomes and long-term survival analysis according to etiology. Orthop Traumatol Surg Res 2012. [Epub ahead of print]

30. Liu J, Li SH, Cai ZD, et al. Outcomes, and factors affecting outcomes, following shoulderhemiarthroplasty for proximal humeral fracture repair. J Orthop Sci. 2011;16(5):565-72.

31. Bufquin T, Hersan A, Hubert L, Massin P. Reverse shoulder arthroplasty for the treatment of three- and four-part fractures of the proximal humerus in the elderly: a prospective review of 43 cases with a short-term follow-up. J Bone Joint Surg Br. 2007;89:516-20.

32. Boyle MJ, Youn SM, Frampton CM, Ball CM: Functional outcomes of reverse shoulder arthroplasty compared with hemiarthroplasty for acute proximal humeral fractures. J Shoulder Elbow Surg 2012. [Epub ahead of print]

33. Murachovsky J, Ikemoto RY, Nas-cimento LG, et al. Pectoralis major tendon reference (PMT): a new method for accurate restoration of humeral length with hemiarthroplasty for fracture. J Shoulder Elbow Surg. 2006;15(6):675-8.

34. Sirveaux F, Navez G, Roche O, Molé D, Williams MD. Reverse prosthesis for proximal humerus fracture, technique and results. Tech Shoulder Elbow Surg. 2008;9:15-22. 